\title{
General Characteristics and Quality of Stroke-Related Online Information - A Cross-Sectional Assessment of the Romanian and Hungarian Websites
} \author{
Valentin Nădășan $4^{*}$ \\ 1. Department of Radiology and Imaging. Emergency County Hospital Tirgu Mures, Romania \\ 2. University of Medicine and Pharmacy of Tirgu Mures, Romania \\ 3. Cardiovascular and Transplant Emergency Institute, Tirgu Mures, Romania \\ 4. Department of Hygiene, University of Medicine and Pharmacy of Tirgu Mures, Romania
}

Septimiu Daniel Popescu¹, Alex Otniel Popescu², Mihaela Dănilă³, Mihaela Dobria², David Maior²,

\begin{abstract}
Background: The quality of online health-related information may affect users' understanding and medical decision-making with dramatic impact, particularly in case of stroke. Objective: The objective of this study was to assess the quality of information about stroke on the Romanian and Hungarian websites in terms of completeness and accuracy. Methods: The research was designed as an observational crosssectional study. The sample included 25 Romanian and 25 Hungarian websites presenting information about stroke for the general public. General characteristics such as website ownership, main goal, website genre and medical approach were identified by the evaluators using a predetermined set of common instructions. The completeness and accuracy of the information were assessed by two independent assessors against a quality benchmark. Results: Overall, most of the websites were owned by private commercial companies (42\%), had educational goal $(66 \%)$, were designed as medical web-portals (46\%) and had a conventional medicine approach (72\%). Mean completeness score was 5.6 points $(S D \pm 1.9)$ for Romanian sites and 4.1 points $(S D \pm 2.4)$ for Hungarian sites $(p=0.017)$. Mean accuracy score was 6.2 points $(S D \pm 1.1)$ for Romanian sites and 7.0 points $(S D \pm 0.7)$ for Hungarian sites $(p=0.02)$. Conclusions: The information about stroke on the Romanian and Hungarian websites had poor quality. Although we found statistically significant differences between the quality scores of the two language sub-samples and two site characteristics associated with significantly higher quality, the practical relevance of these findings for online health information seekers should be interpreted with caution.
\end{abstract}

Keywords: e-health, consumer-health, health-related information, stroke, Eastern-Europe

Received 31 July 2018 / Accepted 14 September 2018

\section{Introduction}

The Internet has become globally one of the main sources of health-related information [1]. In the US, $59 \%$ of the adult population and $72 \%$ of the internet users have looked online for health information [2]. A European study on a representative sample including almost 8000 respondents from seven countries has shown that $44 \%$ of the total sample and $71 \%$ of the internet users, resorted to the Internet to obtain health-related information [1]. Even though Romania was at the bottom of the European countries as far as the percentage of people using the internet to search for health-related information, $47 \%$ of the respondents did use the internet to obtain information about health and disease, according to a statistic published in 2014 [3].

While the Internet has been recognized as a useful educational resource not only for medical professionals but for consumers as well, a number of studies in the field of consumer health informatics have raised several reasons of concern, such as increased exposure of patients to incomplete, inaccurate, misguided or fraudulent health claims

* Correspondence to: Valentin Nădășan

E-mail: valentin.nadasan@umftgm.ro
[4-6]. Misleading online information may have undesired consequences on the patients decision making [7] and there are some indications that even patients needing immediate critical care, such as those affected by stroke, may be exposed to potentially life-threatening information [8].

Although stroke is the second leading cause of mortality [9] and first cause of disability worldwide [9,10], the quality of online information about this condition has not been systematically evaluated.

The main objective of this study was to assess the quality of information about stroke on the Romanian and Hungarian websites in terms of completeness and accuracy.

\section{Methods}

The research was designed as an observational cross-sectional study. The sample included 25 Romanian and 25 Hungarian websites presenting information about stroke for the general public. The search procedure and selection steps are outlined in figure 1. Data acquisition and evaluation was performed during April-May 2018. General characteristics such as website ownership, main goal, website genre and medical approach were identified by the evaluators using a predetermined set of common instructions. The completeness and accuracy of the information were 


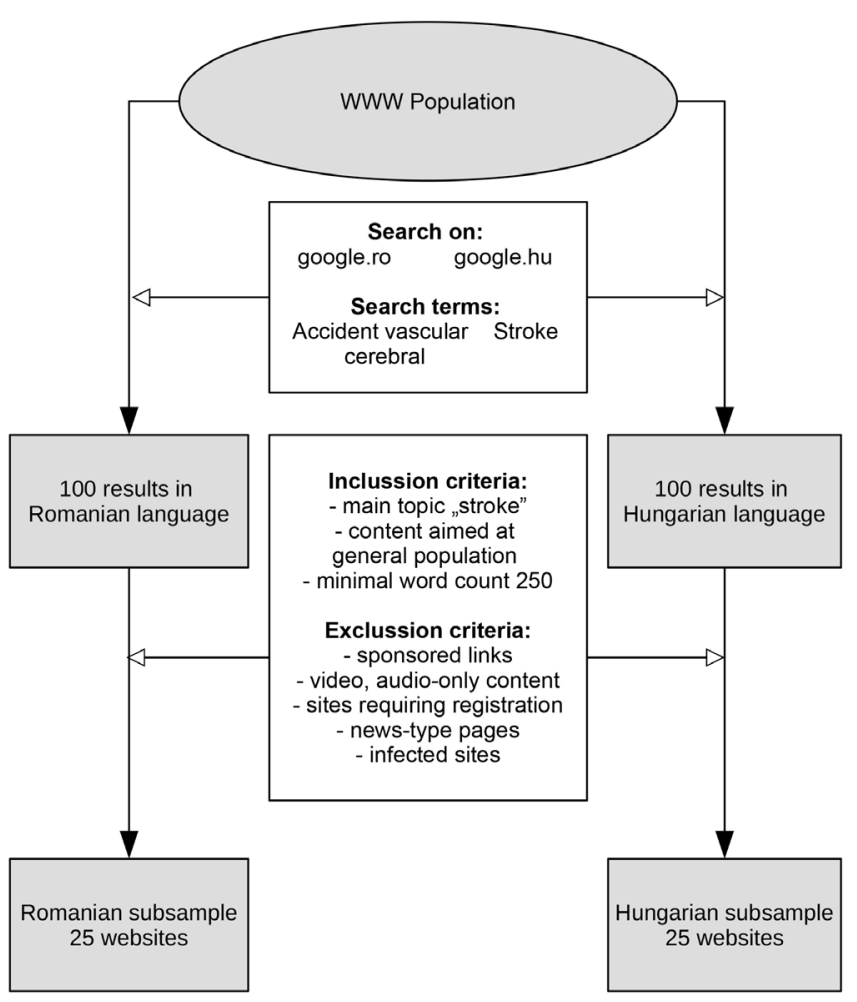

Fig. 1. Search procedure and selection of stroke-related Romanian and Hungarian websites

assessed by two independent assessors against a quality benchmark. The benchmark included 45 items considered relevant for laypersons interested about stroke and was developed from the evidence based literature (the benchmark is available upon request from the corresponding author). The items were reviewed by a neurologist with competence in health education. Completeness and accuracy scores were reported on a decimal scale ( 0 points meaning lowest quality, 10 points showing the highest quality). Completeness and accuracy scores were also computed separately for each of the main chapters of the topic (definition and epidemiology; symptoms and diagnostic; causes and risk factors; primary prevention; first aid and treatment). Selection procedures and assessment methodology are described in detail in previously published works by Nădăşan et al.[11-13].

Descriptive statistics and mean quality scores were calculated for each language sub-sample. Inter-rater agreement was assessed using Cohen's kappa test. Data were checked for normality using the Kolmogorov-Smirnov test. ANOVA test or t-test for independent samples were used as comparison tests for all data with normal distribution. All statistical analyses were performed in SPSS v. 22. The cut-off value for statistical significance was set at $\alpha=0.05$.

\section{Results}

Overall, most of the websites were owned by private commercial companies (42\%), had educational goal (66\%), were designed as medical web-portals (46\%) and had a conventional medicine approach (72\%). The websites classification by general characteristics and language is presented in table I.

The mean relative completeness score of the whole sample $(\mathrm{N}=50)$ was $4.8(\mathrm{SD}=2.3)$ and the mean accuracy score was $6.6(\mathrm{SD}=0.9)$. Five of the websites had completeness scores equal to or above 8 points and 3 of the websites had accuracy scores equal to or above 8 points. Only 1 of the 50 websites had both completeness and accuracy scores above 8 points.

The Kolmogorov-Smirnov test has shown that all data had normal distribution, therefore we used parametric tests for comparison between subcategories. The quality scores of the investigated websites by language and the results of comparison tests between language sub-samples are presented in table II. Chapter specific completeness scores for all 50 websites as a whole, are presented in table III. The mean quality scores by general characteristic and the results of the comparison tests between website categories are presented in table IV.

\section{Discussions}

Overall, the Romanian and Hungarian websites presenting information about stroke for the general public may be characterized as poor. The observed completeness scores of the assessed websites, both Romanian and Hungarian, indicate that the users seeking information about stroke will find only about half of the information considered necessary for a thorough understanding of the topic they are interest in. The comparison test has shown that the mean completeness score of the Romanian stroke-related websites was statistically higher than that of the Hungarian websites ( 5.6 vs. 4.1 points out of $10 ; p=0.017$ ), suggesting a relative superiority of the Romanian websites that might

Table I. Relative frequencies of the stroke-websites by general characteristics and language

\begin{tabular}{|c|c|c|c|}
\hline General characteristics & & Romanian (\%) N=25 & Hungarian (\%) $\mathrm{N}=25$ \\
\hline \multirow{4}{*}{ Ownership } & Foundation, association & 4 & 16 \\
\hline & Health service or product provider & 36 & 24 \\
\hline & Commercial company & 32 & 52 \\
\hline & Not identifiable & 28 & 8 \\
\hline \multirow{2}{*}{ Main goal of the site } & Educational & 64 & 68 \\
\hline & Commercial & 36 & 32 \\
\hline \multirow{3}{*}{ Site genre } & Medical or general portal & 40 & 52 \\
\hline & Online journal or magazine & 24 & 20 \\
\hline & Online shop or company site & 36 & 28 \\
\hline \multirow{2}{*}{ Medical approach } & Conventional medicine & 44 & 100 \\
\hline & Alternative or mixed & 56 & 0 \\
\hline
\end{tabular}


Table II. Comparisons of the completeness and accuracy scores by language sub-samples

\begin{tabular}{llcc}
\hline Scores & Language & Mean (SD) & p-values \\
\hline \multirow{2}{*}{ Relative Completeness Score } & Romanian & $5.6( \pm 1.9)$ & \multirow{2}{*}{$0.017^{\mathrm{a}}$} \\
& Hungarian & $4.1( \pm 2.4)$ & \\
\hline \multirow{2}{*}{ Relative Accuracy Score } & Romanian & $6.2( \pm 1.1)$ & \multirow{2}{*}{$0.020^{\mathrm{a}}$} \\
& Hungarian & $7.0( \pm 0.7)$ & \\
\hline a. t -test for independent samples; SD: standard deviation &
\end{tabular}

-test for independent samples; SD: standard deviation

Table III. Chapter specific relative completeness and accuracy scores

\begin{tabular}{lcc}
\hline Stroke information chapters & $\begin{array}{c}\text { Completeness score } \\
\text { Mean (SD) }\end{array}$ & $\begin{array}{c}\text { Accuracy score } \\
\text { Mean (SD) }\end{array}$ \\
\hline Definition and epidemiology & $6.6( \pm 2.7)$ & $5.9( \pm 2.3)$ \\
Symptoms and diagnostics & $5.8( \pm 2.6)$ & $8.5( \pm 2.2)$ \\
Causes and risk factors & $5.1( \pm 3.0)$ & $5.0( \pm 2.6)$ \\
Primary prevention measures & $4.8( \pm 3.9)$ & $5.8( \pm 3.6)$ \\
First aid and treatment & $4.0( \pm 2.7)$ & $6.1( \pm 2.8)$ \\
\hline
\end{tabular}

SD: standard deviation

be of relevance for the bilingual Transylvanian population from Romania. However, because the difference is very small and both scores remain well within a level that, realistically speaking, may be characterized as rather modest, the statistical difference does not translate into a practi$\mathrm{cal}$, real-life advantage in terms of online documentation. In fact, the users' likelihood of landing on web-pages providing incomplete information about stroke remains very high no matter which of the two languages the users is familiar with.

The results regarding accuracy of online stroke-related information are slightly higher compared to those regarding completeness. While accuracy scores are less than one decimal point higher on average than completeness scores on the Romanian-language sites, the accuracy scores on the Hungarian-language sites are approximately three decimal points higher compared to the completeness scores. Although accuracy of the Hungarian stroke-related web-pages may be qualified as acceptable (7 points out of 10), and was found statistically significantly higher compared to the accuracy of the Romanian web-pages, advising bilingual users to rely preferentially on the information provided by the Hungarian language sites may not be warranted since these same Hungarian-language websites had poor ratings as far as completeness is concerned.

On one hand, the analysis of completeness and accuracy at the level of specific chapters has shown that most of the chapters had scores spread, as expected, around the mean values ( 4.8 and 6.6 respectively). On the other hand, the chapter-focused analysis revealed on the positive side that the section describing the symptoms of stroke had the highest score on accuracy ( 8.5 points out of 10 ), and on the negative side, the very chapter dealing with life-saving measures when suspecting a stroke-related emergency situation, recorded the lowest score on completeness ( 4 points out of 10).

Since the number of sites with consistently high scores (both scores above 8 points) was extremely low, users who search information about stroke on the Romanian and/ or Hungarian websites may have a very high likelihood of being misinformed either because of the failure to obtain important information or because of being provided inaccurate information. Theoretically, the inconvenience of incomplete information could be mitigated by getting information from several sites with possibly complementary information. Practically, this strategy would require highly motivated users with ability to put together information obtained from several sources, and last but not least, it is time consuming.

The analysis of quality scores in relation to the general characteristic of the stroke-related websites has shown that completeness is not associated with any of the websites' characteristics. As far as accuracy, the tests have identified two characteristics that seem to be associated with websites accuracy (see table 4). Firstly, the websites owned by commercial companies had the highest accuracy scores (7 points out of 10) while those with unidentifiable ownership had the lowest accuracy score (6 points, out of 10). If future studies will confirm this association as being consistent on other topics besides stroke and also in other languages besides Romanian and Hungarian, users could be advised to check website ownership in order to get a clue about the quality of the information found on the respective web-page. Secondly, conventional medicine websites were associated with significantly higher accuracy scores (6.8 points out of 10) compared to alternative medicine websites, including websites with a mixed approach (5.9 points out ot ten). If confirmed, this association also might serve as friendly predictor of website accuracy for users with no medical background.

Table IV. Mean values of the relative completeness and accuracy scores by website general characteristics

\begin{tabular}{|c|c|c|c|c|c|}
\hline General characteristics & & $\begin{array}{c}\text { RCS } \\
\text { Mean (SD) }\end{array}$ & p-value & $\begin{array}{c}\text { RAS } \\
\text { Mean (SD) } \\
\end{array}$ & p-value \\
\hline \multirow{4}{*}{ Ownership } & Foundation, association & $3.8( \pm 2.9)$ & \multirow{4}{*}{$0.339 a$} & $6.5( \pm 1.2)$ & \multirow{4}{*}{$0.029^{a}$} \\
\hline & Health service or product provider & $4.2( \pm 1.9)$ & & $6.4( \pm 1.0)$ & \\
\hline & Commercial company & $5.3( \pm 2.5)$ & & $7.0( \pm 0.8)$ & \\
\hline & Not identifiable & $5.2( \pm 2.0)$ & & $6.0( \pm 0.9)$ & \\
\hline \multirow{2}{*}{ Main goal } & Educational & $5.0( \pm 2.4)$ & \multirow{2}{*}{$0.394^{b}$} & $6.6( \pm 1.0)$ & \multirow{2}{*}{$0.973^{b}$} \\
\hline & Commercial & $4.4( \pm 2.1)$ & & $6.5( \pm 0.9)$ & \\
\hline \multirow{3}{*}{ Site genre } & Medical or general portal & $5.3( \pm 2.6)$ & \multirow{3}{*}{$0.477^{a}$} & $6.6( \pm 0.9)$ & \multirow{3}{*}{$0.957^{a}$} \\
\hline & Online journal or magazine & $4.6( \pm 2.0)$ & & $6.5( \pm 1.2)$ & \\
\hline & Online shop or company site & $4.4( \pm 2.1)$ & & $6.6( \pm 0.9)$ & \\
\hline \multirow{2}{*}{ Medical approach } & Conventional medicine & $4.6( \pm 2.5)$ & \multirow{2}{*}{$0.382^{\mathrm{b}}$} & $6.8( \pm 0.8)$ & \multirow{2}{*}{$0.002^{\mathrm{b}}$} \\
\hline & Alternative or mixed & $5.3( \pm 1.9)$ & & $5.9( \pm 1.1)$ & \\
\hline
\end{tabular}

RCS: relative completeness score; RAS: relative accuracy score; SD: standard deviation; a: ANOVA; b: $t$ test for independent samples 
Generally, the findings of this study are consistent with many other studies investigating the quality of online information about various medical conditions, both on the Romanian internet [11-15] as well as on the English, Spanish or other language websites [16-26]. With a few exceptions, most of the authors have reported modest completeness and accuracy scores but, it should be noted the heterogeneity of methodologies and evaluation tools applied in these studies prevents a rigorous comparison. As far as stroke-related information on the internet, the only study that evaluated the quality of information about this topic along with heart attack included a sample of Portuguese-language websites and concluded that the quality of online information on stroke was acceptable although frequently incomplete [27].

\section{Strenghts and limitations}

To the best of our knowledge, this is the first study assessing the quality of stroke-related information on the Romanian and Hungarian websites addressing the general population. The results of the study may provide individuals seeking information about stroke valuable insights on how to find the most complete and accurate online sources of information about stroke.

Another strength that merits to be highlighted is that we used two distinct scores to measure completeness and accuracy in contrast with most other tools which measure and report an overall score that does not distinguish quantitative and qualitative criteria. However, it is important to remember that the accuracy score, by design, measures only the correctness of the information presented on the website, and thus it should be interpreted only in relation with the completeness score.

Basically, the limitations of the study include those that are implicit to internet research. For example, the replication of the study might render different results due to: ongoing changes of the online content; using different search terms; using other search engines than Google. Another type of limitation that needs to be discussed is related to the subjective nature of the evaluators. It is known that ratings of the web-page content is somewhat dependent on the evaluators professional background [28]. In order to increase the level of objectivity of the assessment, the evaluations were performed by health professionals or medical students, all evaluators followed a common set of detailed instructions and, each website was assessed by two independent evaluators. After inter-grader agreement was statistically checked using Cohen's kappa test, a consensus evaluation was performed whenever it was necessary (kappa $<0,8)$. Another limitation that should be clarified is the apparently small number of websites evaluated for each language. In this context, it should be pointed out that research on the users searching behavior has shown that the majority of internet users access only the websites included on the first page of the Google search results [29], therefore, the websites included in the present study covered the content browsed by most users with a generous margin of error. Finally, since our sample included only Romanian and Hungarian websites about stroke, the results of the study can not be generalized to other languages or other health-topics. In as much as Romanian and Hungarian educated users are visiting English websites for health-related purposes, it would be warranted that future studies assess the completeness and accuracy of these websites.

\section{Conclusions}

1. Overall, the information about stroke on the Romanian and Hungarian websites had poor and variable quality. Only half of the information considered necessary for a good understanding of stroke by users was present on the investigated sites.

2. Statistically, the completeness of stroke-related information on the Romanian language websites was significantly higher than on the Hungarian language websites, while the accuracy was significantly higher on the Hungarian-language websites. However, the differences were too small to offer a practical advantage to users of a particular language during online information seeking.

3. The completeness of stroke-related information was not associated with any of the general characteristics on the Romanian and Hungarian websites included in our sample. Although the accuracy of stroke-related information was associated with two of the investigated general characteristics, these associations need confirmation and must be interpreted with caution as far as their practical relevance.

\section{Acknowledgements}

We thank Sorin Săndulache $\mathrm{MD}, \mathrm{PhD}$, neurologist at Colentina Hospital, Bucharest, Romania for his valuable input in the development of the quality becnhmark for the stroke-related websites. Also, we thank Dalma Kasza, medical student at the University of Medicine and Pharmacy of Tîrgu Mures, Romania for her contribution to data acquisition.

\section{Authors' contribution}

SDP - Conceptualization, data curation, formal analysis, investigation, project administration, writing original draft; Writing - review \& editing)

AOP - Data curation, formal analysis, investigation, writing original draft, final approval

M Dănilă - Data curation, investigation, writing original draft, final approval

M Dobria - Data curation, writing original draft, final approval

DM - Data curation, writing original draft, final approval VN - Conceptualization, formal analysis, methodology, supervision, visualization, writing review and editing

\section{Conflict of interest}

None to declare. 


\section{References}

1. Andreassen HK, Bujnowska-Fedak MM, Chronaki CE et al. European citizens' use of E-health services: a study of seven countries. BMC Public Health. 2007; 10:53.

2. Fox S, Duggan M. Health Online 2013. Pew Internet Project. Online: http://www.pewinternet.org/ /media//Files/Reports/PIP_HealthOnline. pdf Accessed: 29.07.2018.

3. Statista.com. Share of Europeans who use the internet to search for health-related information in 2014. Online: https://www.statista.com/ statistics/451258/internet-use-for-health-related-information-europe/ Accessed: 29.07.2018.

4. Hoffmann D, Schwartz J. Stopping deceptive health claims: the need for a private right of action under federal law. Am J Law Med. 2016;42:5384.

5. Eysenbach G, Powell J, Kuss O, Sa ER. Empirical studies assessing the quality of health information for consumers on the world wide web: a systematic review. JAMA. 2002;287:2691-2700.

6. Nădășan V. The Quality of Online Health-Related Information-an Emergent Consumer Health Issue. Acta Medica Marisiensis. 2016;62:408-421.

7. Santana S, Lausen B, Bujnowska-Fedak M, Chronaki CE, Prokosch HU, Wynn R. Informed citizen and empowered citizen in health: results from an European survey. BMC Fam Pract. 2011;12:20.

8. Nădășan V. Should Critical Care Professionals Take Hoaxes/Rumours Seriously? J Crit Care Med (Targu Mures). 2016;2:205-206.

9. Johnson W, Onuma O, Owolabic M, Sachde S. Stroke: a global response is needed . Online: http://www.who.int/bulletin/volumes/94/9/16-181636/ en/. Accessed: 30.07.2018.

10. CDC. Stroke Facts-Stroke Statistics, 2017. Online: https://www.cdc. gov/stroke/facts.htm. Accessed: 30.07.2018.

11. Nădășan V, Roșca AN, Tarcea M, Ábrám Z, Mărușteri M. The Quality of Romanian Breast Cancer Websites: a Five-Year Longitudinal Assessment. J Cancer Educ. 2018;33:703-707.

12. Nădășan V, Moldovan O. The Completeness and Accuracy of Information about Coeliac Disease on the Romanian Websites. Journal of Applied Quantitative Methods. 2016;11:70-76.

13. Nădășan V, Vancea G, Georgescu PA, Tarcea M, Abram Z. The credibility, completeness and accuracy of information about first aid in case of choking on the Romanian Websites. Journal of Applied Quantitative Methods. 2011;6:18-26.

14. Nădășan V, Moldovan G, Tarcea M, Ureche R. Edified or confused? How complete and accurate is the information about vitamin B12 on the Romanian Websites? Revista de Igienă și Sănătate Publică, Timișoara. 2011;61:49-57.
15. Nădășan V, Voidăzan S, Tarcea M, Ureche R. The quality of information about influenza on the Romanian Internet. Acta Medica Transilvanica. 2011:2:312-4.

16. Unal B, Critchley JA, Capewell S. Missing, mediocre, or merely obsolete? An evaluation of UK data sources for coronary heart disease. J Epidemiol Community Health. 2003;57:530-5.

17. Ching T, Roake JA, Lewis DR. Net-based information on varicose vein treatments: a tangled web. N Z Med J. 2010;123:9-15.

18. Killeen S, Hennessey A, El Hassan $Y$, et al. Gastric cancer-related information on the Internet: incomplete, poorly accessible, and overly commercial. Am J Surg. 2011;201:171-8.

19. Ream E, Blows E, Scanlon K, Richardson A. An investigation of the quality of breast cancer information provided on the internet by voluntary organisations in Great Britain. Patient Educ Couns. 2009;76:10-5.

20. Ni Riordain R, McCreary C. Head and neck cancer information on the internet: type, accuracy and content. Oral Oncol. 2009;45:675-7.

21. López-Jornet P, Camacho-Alonso F. The quality of internet sites providing information relating to oral cancer. Oral Oncol. 2009;45:e95-8.

22. Dulaney C, Barrett OC, Rais-Bahrami S, Wakefield D, Fiveash J, Dobelbower M. Quality of Prostate Cancer Treatment Information on Cancer Center Websites. Cureus. 2016;8:e580.

23. Lawrentschuk N, Abouassaly R, Hackett N, Groll R, Fleshner NE. Health information quality on the internet in urological oncology: a multilingual longitudinal evaluation. Urology. 2009;74:1058-63.

24. Ostry A, Young ML, Hughes M. The quality of nutritional information available on popular websites: a content analysis. Health Educ Res. 2008;23:648-55.

25. Morr S, Shanti N, Carrer A, Kubeck J, Gerling MC. Quality of information concerning cervical disc herniation on the Internet. Spine J. 2010;10:350-

26. Yermilov I, Chow W, Devgan L, Makary MA, Ko CY. What is the quality of surgery-related information on the internet? Lessons learned from a standardized evaluation of 10 common operations. J Am Coll Surg. 2008;207:580-6

27. Bastos A, Paiva D, Azevedo A. Quality of health information on acute myocardial infarction and stroke in the world wide web. Acta Med Port. 2014;27:223-31.

28. Cerminara C, Santarone ME, Casarelli L, Curatolo P, El Malhany N. Use of the DISCERN tool for evaluating web searches in childhood epilepsy. Epilepsy Behav. 2014;41:119-21.

29. Granka LA, Joachims T, Gay G. Eye-Tracking Analysis of User Behavior in WWW Search. Online:www.cs.cornell.edu/people/tj/publications/ granka_etal_04a.pdf. Accessed: 29.07.2018. 